\title{
Comparative analysis of semi-active control algorithms applied to magnetorheological dampers
}

\author{
Análisis comparativo de algoritmos de control semi-activo \\ aplicados a amortiguadores magnetoreológicos
}

\author{
Luis A. Lara V. ${ }^{*} \quad$ José L.V. Brito $^{2} \quad$ Yamile Valencia G. $^{1}$ \\ Received: December 16, 2014, accepted: March 24, 2016 \\ Recibido 16 de diciembre de 2014 Aceptado 24 de marzo de 2016
}

\begin{abstract}
This paper analyzes the performance of three different semi-active control algorithms used to calculate and manage the optimal damping forces generated by a pair of magnetorheological (MR) dampers installed in a two-story building. The semi-active algorithms used are the linear quadratic regulator (LQR) associated with the clipped optimal algorithm, an algorithm based on a prediction model and a dynamic inverse model using nonlinear autoregressive exogenous (NARX)-type artificial neural networks, and a decision-making algorithm based on fuzzy logic. Additionally, the performances of the proposed semi-active algorithms are compared to those of passively used control devices. The results show response value reductions exceeding $50 \%$ for all the semi-active control strategies, which considerably outperformed the passive control. The three control strategies are thus confirmed as interesting tools with potential applications as MR damper administrators.
\end{abstract}

Keywords: Structure dynamics, semi-active control of structures, vibration reduction, magnetorheological dampers, control algorithms, intelligent systems.

\section{RESUMEN}

En este artículo se analiza numéricamente la eficiencia y el desempeño de tres diferentes algoritmos de control semiactivo que tienen la función de calcular y administrar las fuerzas óptimas de amortiguamiento que deben ser generadas por un par de amortiguadores magnetoreológicos instalados en una estructura de dos niveles. Los algoritmos semi-activos empleados son el regulador lineal cuadrático $(L Q R)$, asociado al algoritmo clipped optimal y dos algoritmos fundamentados en sistemas inteligentes: un algoritmo basado en un modelo de predicción y en un modelo inverso dinámico construidos por medio de redes neuronales artificiales de tipo NARX y un algoritmo de toma de decisiones basados en lógica difusa. Adicionalmente, la actuación de los algoritmos de control semi-activo propuestos es comparada con el desempeño de los dispositivos de control utilizados de forma pasiva. Los resultados obtenidos mostraron en todos los casos analizados, valores de reducción de respuesta superiores a $50 \%$ para todas las estrategias de control semiactivo empleadas, superando ampliamente el desempeño del control pasivo analizado. De esta forma fue posible confirmar que las tres estrategias de control desarrolladas demostraron ser herramientas eficientes, robustas y confiables para ser utilizadas como administradoras de amortiguadores magnetoreológicos.

Palabras clave: Dinámica de estructuras, control semiactivo de estructuras, reducción de vibraciones, amortiguadores magnetoreológicos, algoritmos de control, sistemas inteligentes.

1 Departamento de Ingeniería Civil. Universidad Nacional de Colombia sede Medellín. Carrera 80 Nº 65-223 - Núcleo Robledo. Medellín, Colombia.E-mail: lualarava@unal.edu.co; yvalenc0@unal.edu.co

2 Departamento de Engenharia Civil e Ambiental. Universidade de Brasília. Campus Universitário Darcy Ribeiro - CEP 70910900. Brasilia, Brasil.E-mail:jlbrito@unb.br

* Corresponding Author 


\section{INTRODUCTION}

Structural control is a method to reduce the demand of energy disruption in structural components by altering structural mechanical properties. In the literature, structural control is typically classified in terms of four subtypes: passive control, active control, hybrid control, and semiactive control [1-3]. The first two-passive and active controls- represent opposite control theories; passive systems do not require external power sources to dissipate energy in the system, whereas active systems rely on the injection of large amounts of energy to introduce forces in controlled structural systems. In contrast, hybrid control and semiactive control strategies fall between active and passive systems, using some of the properties and advantages of each [4-7].

In hybrid systems, control is achieved through a combination of the functionalities of the passive and active systems: The devices are programmed to initially act passively, only behaving differently when the passive system's capabilities are overcome by the demands of the acting excited structure. In this case, an external force is introduced to the system to improve the performance of the control device [2]. Semiactive control systems also operate differently, modifying the properties of the controlled system by inserting small amounts of energy and enabling the system to function with portable sources of external energy, such as batteries [6, 8-9].

This last class of systems includes attractive devices that present the same benefits and performance as active systems without requiring the large amounts of energy typically needed to power energy-dissipating devices. One of the most promising systems is the magnetorheological (MR) damper, a semiactive device comprising a hydraulic cylinder, magnetic coils, and start fluid known as MR fluid. The main feature of this device is its ability to reversibly change from a linear viscous free-flowing state to a semi-solid state in milliseconds when exposed to a magnetic field. This ability makes MR dampers appropriate for the control of structural systems because they can be used to change the damping forces easily, quickly, and safely and are relatively low cost $[4,10-11]$.

Thus, many studies have focused on developing control algorithms that take advantage of MR dampers' characteristics. Among the most interesting proposals addressing the development of control algorithms is the control strategy developed in [4], which suggested using a clipped optimal controller based on acceleration feedback. This algorithm has been employed in various buildings with isolated bases [12], in seismic control nonlinear buildings [13], to reduce vibrations on cable-stayed bridges [14], and to provide seismic protection of highway bridges [15].

Another commonly used approach to administrate MR dampers is based on the use of artificial intelligence techniques. Among such algorithms, those based on artificial neural networks (ANNs) and fuzzy logic stand out. Neural network-based controllers were employed in [16-20]. These algorithms generally operate as predictive models, where the main objective is to determine the actions to be executed by energy-dissipating devices to reduce the system's response to dynamic actions. Additionally controllers employing fuzzy logic act by continually adjusting the dampers' control forces using a set of rules representing the heuristic knowledge of the particular system [9, 21-25].

In this paper, we analyze the numerical performance of three different control strategies to administrate MR dampers' command signals to apply control forces and thereby reduce the structural response of a two-story frame system subjected to the actions of external excitations. The proposed analytical algorithms include the linear-quadratic regulator (LQR) associated with the clipped optimal algorithm, an algorithm based on nonlinear autoregressive exogenous (NARX)-type ANNs, and a decision-making algorithm based on fuzzy logic. The results showed that the three control strategies presented significant reductions in response, making these strategies, interesting to use in structures control tools.

\section{SEMI-ACTIVE CONTROL USING THE LQR ASSOCIATED WITH THE CLIPPED OPTIMAL ALGORITHM}

Consider a structural system of $\mathrm{n}$ degrees of freedom whose dynamic behavior is governed by the following matrix equation of motion:

$$
M \ddot{x}(t)+C \dot{x}(t)+K x(t)=D u(t)+E f(t)
$$


The following set of simultaneous first-order differential equations, commonly known as state equations, facilitates handling equation (1):

$$
\dot{z}(t)=A z(t)+B u(t)+H f(t), z(0)=z_{0}
$$

where:

$$
z(t)=\left[\begin{array}{c}
x(t) \\
\dot{x}(t)
\end{array}\right]
$$

This is the state vector of dimension $(2 n)$, and $x(t)$ is the displacement vector of order $(n)$.

$$
A=\left[\begin{array}{cc}
0 & I \\
-M^{-1} D & -M^{-1} C
\end{array}\right]
$$

This is the state matrix system of order $(2 n x 2 n)$, with 0 being a null matrix of order $(n x n)$ and $I$ an identity matrix of order $(n \times n)$.

$$
B=\left[\begin{array}{c}
0 \\
M^{-1} D
\end{array}\right] H=\left[\begin{array}{c}
0 \\
M^{-1} E
\end{array}\right]
$$

These are localization matrices of order $(2 n \times m)$ and ( $2 n x r)$, respectively, and matrices $D$ and $E$ establish the position of the control devices and the external excitation in the state equation.

Finally, $M, C$ and $K$ are matrices of the mass, damping, and stiffness of order $(n \times n) ; x(t)$ is the displacement vector of dimension $(n) ; f(t)$ is the vector of dimension $(r)$ representing the load applied to the system; and $u(t)$ is the dimensional vector $(m)$ representing the control force. Matrices $D$ and $E$ are of the orders $(n \times m)$ and $(n \times r)$ and define the locations of the control forces (positions of the $\mathrm{m}$ controllers) and external stimuli (positions of $\mathrm{r}$ external forces), respectively.

The main difficulty in using the LQR is selecting a control vector $u(t)$ to minimize the performance index $J$ in the system state equation. The shape of the performance index $J$ is quadratic in $z(t)$ and $u(t)$ for the specific case of structural control. Thus, if $t_{0}=0$, the performance index $J$ can be represented as follows:

$$
J=\int_{0}^{t_{f}}\left[z^{T}(t) Q z(t)+u^{T}(t) R u(t)\right] d t
$$

where $Q$ is a positive semi-defined matrix of order $(2 n \times 2 n)$ and $R$ is a positive defined matrix of order $(m \times m)$. These matrices are commonly described as weighted because their magnitudes are defined according to the relative importance of the state variables and control forces in the minimization process.

To solve the problem of an LQR with $J$ defined by equation (6) subject to the system-imposed restriction described in equation (2), the Lagrangian $L$ is generated by grouping these two equations in a Lagrange multiplier variable at time $\lambda(t)$.

$L=\int_{0}^{t_{f}}\left\{\begin{array}{c}z^{T}(t) Q z(t)+u^{T}(t) R u(t)+\lambda^{T}(t) \\ {[A z(t)+B u(t)+H f(t)-\dot{z}(t)]}\end{array}\right\} d t$

The Lagrange multiplier $\lambda(t)$ is also known as the costate vector and ensures that the equation of state is considered in the minimization process.

The conditions that define the optimal control can be found using the first derivative of the Lagrangian in relation to the state and control variables and equating this expression to zero. The first variation of the Lagrangian is as follows:

$$
\begin{gathered}
\delta L=-\lambda^{T}\left(t_{f}\right) \delta z\left(t_{f}\right)+\lambda^{T}(0) \delta z(0)+ \\
\int_{0}^{t_{f}}\left[\left(\dot{\lambda}^{T}+\frac{\partial H}{\partial_{z}}\right) \delta z+\frac{\partial H}{\partial_{u}} \delta u\right] d t
\end{gathered}
$$

where $H$ is the Hamiltonian defined as the integrand in equation (7).

Starting from the initial condition of equation (1), it can be concluded that $\delta z(0)$. As required, $\delta L=0$, and thus:

$$
\begin{array}{cc}
\frac{\partial H}{\partial_{u}}=0, & 0 \leq t \leq t_{f} \\
\dot{\lambda}^{T}+\frac{\partial H}{\partial_{u}}=0, & 0 \leq t \leq t_{f}
\end{array}
$$

The boundary condition is:

$$
\lambda^{T}\left(t_{f}\right)=0
$$


Partially differentiating $H$ in terms of $u$ and $z$ produces:

$$
\begin{gathered}
\dot{\lambda}=-A^{T} \lambda-2 Q Z, \quad \lambda\left(t_{f}\right)=0 \\
u=-\frac{1}{2} R^{-1} B^{T} \lambda
\end{gathered}
$$

The set of equations (2), (12), and (13) provide the optimal solution for $z(t), u(t)$ and $\lambda(t)$. Particularly, equation (13) is the term of optimal control expressed as co-state function, therefore, the relationship between the costate where the state must be determined. To this end, the control vector is assumed to be regulated by the state vector; that is, closed-loop control is implemented, and the system's structural response is continuously monitored. This information can then be used to make permanent corrections to the applied control forces. Thus, assuming that the relationship between the costate and state is linear, we have:

$$
\lambda(t)=P(t) z(t)
$$

Matrix $P(t)$ is obtained by differentiating equation (14) in time, which gives:

$$
\dot{\lambda}(t)=\dot{P}(t) z(t)+P(t) \dot{z}(t)
$$

Substituting equations (2), (13), (14), and (15) into equation (12) yields:

$$
\left[\begin{array}{c}
\dot{P}(t)+P(t) A-\frac{1}{2} P(t) B R^{-1} \\
B^{T} P(t)+A^{T} P(t)+2 Q \\
z(t)+P(t) H f(t)=0 \\
P\left(t_{f}\right)=0
\end{array}\right.
$$

Assuming that $f(t)=0$, equation (16) can be reduced to:

$$
\begin{array}{ll}
\dot{P}(t)+P(t) A-\frac{1}{2} P(t) B R^{-1} B^{T} P(t)+ \\
A^{T} P(t)+2 Q=0, & P\left(t_{f}\right)=0
\end{array}
$$

In the optimal control theory, equation (16) is called the Riccati equation matrix, where $P(t)$ is the Riccati matrix. Because $P(t)$ is specified in terms of $t_{f}$, this equation can be solved retroactively in time.

Substituting equation (14) into equation (13) shows that the control vector $u(t)$ is linear in $z(t)$. Thus, the law of optimal control is:

$$
u(t)=G(t) z(t)=\frac{1}{2} R^{-1} B^{T} P(t) z(t)
$$

where $G(t)$ is the control gain.

Strictly speaking, the Riccati matrix $P(t)$ obtained from equation (16) does not provide an optimal solution unless the excitation term $f(t)$ disappears within the control interval $\left[0, t_{f}\right]$ or undergoes a stochastic white noise-type process. In structural applications, numerical calculations have shown that the Riccati matrix generally remains constant in the control range but rapidly decreases to zero as it approaches $t_{f}$. Thus, in most cases, $P(t)$ can be approximated as a constant matrix $P$, allowing the Riccati equation to be reduced to:

$$
P A-\frac{1}{2} P B R^{-1} B^{T} P+A^{T} P+2 Q=0
$$

Thus, the control gain also becomes a constant characterized by the following expression:

$$
G=-\frac{1}{2} R^{-1} B^{T} P
$$

Finally, substituting equation (18) into equation (2) allows the behavior of the controlled structure to be determined:

$$
\begin{gathered}
\dot{z}(t)=(A+B G) z(t)+H f(t) \\
z(0)=z_{0}
\end{gathered}
$$

It must be emphasized that the optimal control law described in equation (18) requires total knowledge of the structure's state vector $z(t)$ (a situation referred to as state feedback). However, the state vector can rarely be measured directly, and as a result, it must be replaced by an estimated state vector $\hat{z}(t)$ determined using incomplete measurements of state; this situation is known as output feedback.

Once the optimal control law has been defined, it is possible to determine the forces that the MR 
dampers must supply to the system to control the vibrations. Below, the procedure for selecting the control device's command signal is explained.

Because increases and reductions of the forces produced by the MR damper are only controlled indirectly via the voltage applied to the device, that voltage must be characterized to generate forces close to those considered to be ideal. To this end, the clipped optimal algorithm developed in [4] is used to select the command signal.

The clipped optimal algorithm is relatively simple and ensures that the voltage remains stable when the damper supplies forces with values close to the desired optimum. If the magnitude of the damperproduced forces is below the desired optimum and the two forces have same sign, then the voltage applied will be the maximum allowed, and the force produced by the damper will be adjusted incrementally until it is as close as possible to the desired control force magnitude. If the opposite condition prevails, then the command voltage will be zero. Thus, the algorithm used to select the voltage to be applied to the MR dampers is given by:

$$
v_{i}=V_{\max } H\left(\left(u_{c}-u\right) u\right)
$$

where $V_{\max }$ is the voltage at which the magnetic field of the control device is saturated, $H$ is a unit step function, $u_{c}$ is the desired control force, and $u$ is the force actually produced by the $M R$ damper. Figure 1 presents the algorithm graphically.

Although the LQR is a linear control strategy, the nonlinearity that characterizes structural control and facilitates the use of MR dampers as control devices can be achieved using the abovementioned voltage-selection algorithm to accommodate the nonlinearities in the control project by comparing the damper-generated forces with the desired forces and bringing them closer together.

\section{SEMI-ACTIVE CONTROL USING ANNS BASED ON A NONLINEAR AUTOREGRESSIVE MODEL WITH EXOGENOUS INPUTS}

The second control device used in this work is based on a predictive model and an inverse dynamic model developed using ANNs. In the case of the developed

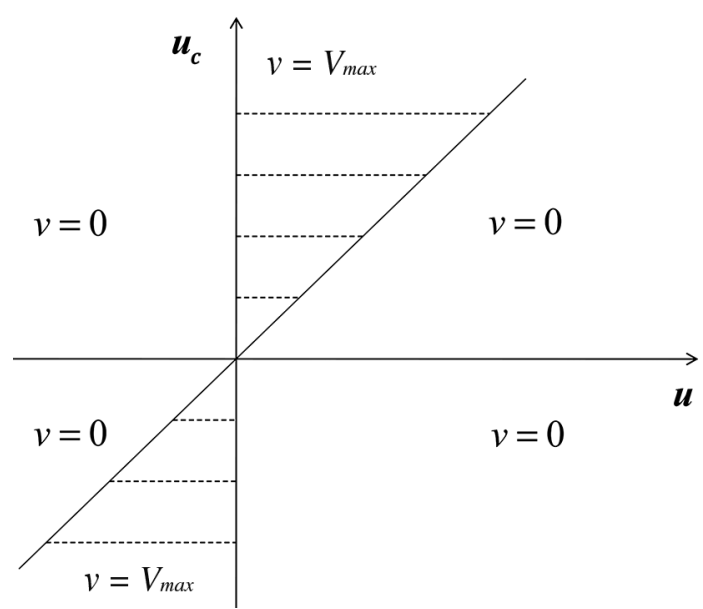

Figure 1. Graph representing the MR damper voltage-selection algorithm.

inverse model, the ANNs' output (voltage) is part of the input of the mechanical model of the control device, and the inputs of the neural network are the output values produced by the mechanical model (the phenomenological model developed in [26]) and the response values of the structural system in question. Accordingly, the controller calculates the correct voltage to be applied to the control mechanisms based on the system response, the calculated optimal control force, and the voltage values in the immediately preceding moments. The optimal control force is calculated using a predictive model developed based on a recurrent neural network customized for that purpose.

The primary objective of the ANN-based control algorithm is to define a model capable of calculating the optimal control force to be applied by the energy-dissipating mechanism to minimize the movement of the protected structure. However, the control design must also determine the voltage to be applied to the controller because the increasing or reducing of the forces produced by the MR damper is controlled indirectly by varying the voltage applied to the device. To determine these two fundamental parameters -the optimal force and optimal voltage- two NARX networks were used. The first network simulates a predictive model designed to determine the optimal control force required for the MR damper to minimize, with maximum efficiency, the vibrations in the structure when it is subjected to the action of external forces. The 
second network functions as an inverse model; that is, it determines the inputs to the controller based on the system's delayed outputs. Thus, the second network must define the appropriate voltage to be applied to the control device so that a near-optimal force, as calculated by the first neural network, is transmitted to the structure.

Figure 2 shows an ANN-based control system for reducing the vibrations in a structure.

The predictive model for the optimal force used to control a two-story structure consists of a NARX-type ANN that is totally interconnected and configured with a layer of sensor units consisting of fifteen input signals and a bias term, a computational processing layer comprising sixteen hidden neurons, and a results layer consisting of a single outlet (output). A representation of the network used in this predictive model for the force is shown in Figure 3.

Based on the results obtained in [27], the order of the network input delays was equal to two. Thus, the values of the selected inputs (displacement, velocity, and acceleration of the first floor of the structure and voltage) and the output values of the model that are fed back into the system were assigned delays of one and two units, as shown in Figure 3.
The activation functions used between the sensor nodes and the hidden layer neurons were all hyperbolic tangent sigmoid functions, whereas a linear function by parts was used for the passage of data between the hidden layer neurons and the network output. The Levenberg-Marquardt algorithm was used as the training algorithm to adjust the weightings of the synaptic connections among the neurons of the proposed network.

The inverse model proposed to determine the voltage to be applied to the dissipating devices consists of a

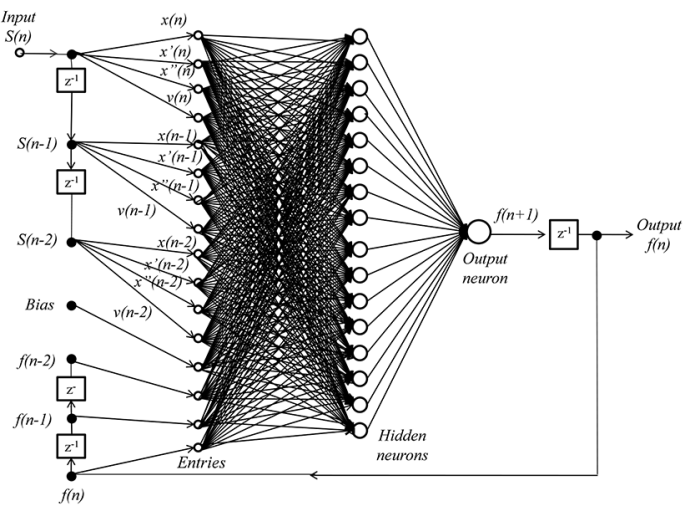

Figure 3. ANARX-type network used in the predictive model for the optimal control force.

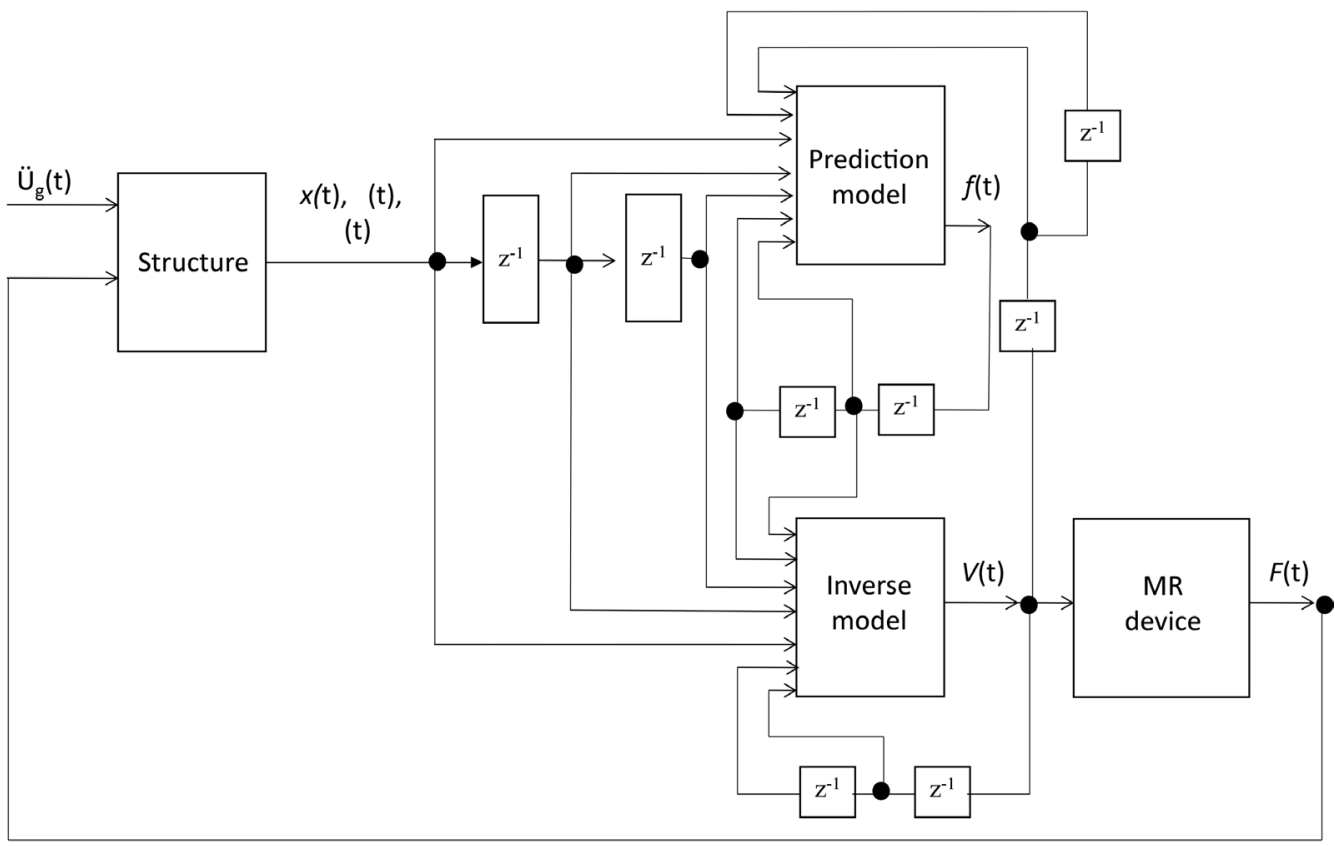

Figure 2. Design of a control model using ANNs. 
totally interconnected NARX-type network. As in the predictive model, the network is configured with a layer of sensor nodes including fifteen input signals and one bias term, a computational processing layer consisting of sixteen hidden neurons, and a results layer comprising a single output unit.

The input layer of the inverse model consists of the values for the displacement, velocity, and acceleration of the first floor of the structure to be analyzed added to the values for the optimal control force calculated by the predictive model and the recurrent network's feedback in the form of output value (voltage). The activation functions used in the inverse model are the same as those used in the predictive model, that is, hyperbolic tangent sigmoid functions in the inputprocessors step and a linear function by parts in the processor-output step. The choice of the order of the delay lines in the network was also based on the results obtained in [27]. Figure 4 shows the neural model used in the inverse model.

Specific details of the construction and training of the optimal force predictive model and the inverse model used to determine the control device voltage in this work can be found in [28].

\section{SEMI-ACTIVE CONTROL USING FUZZY LOGIC}

The last control design tested is based on fuzzy logic, which is also known as diffuse logic and consists of a series of adjustments, usually intuitive and

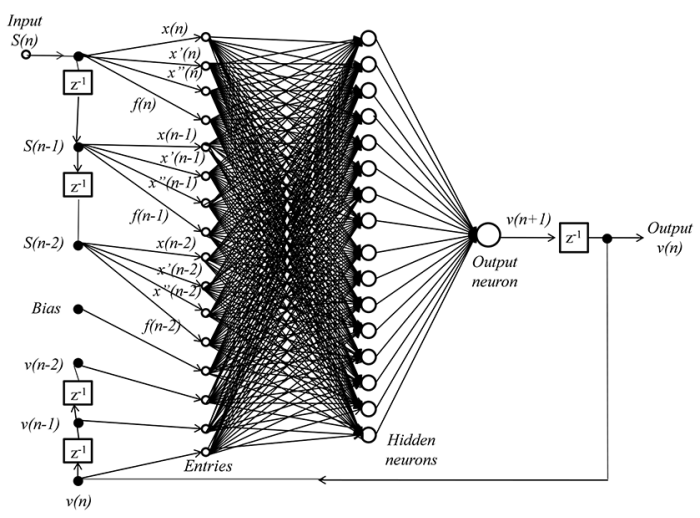

Figure 4. A NARX-type network used in the inverse model to determine the control device voltage. easy to understand, determined by observing and rationalizing the behavior of the structural system under analysis.

Fuzzy logic is a robust, efficient, and fundamentally pragmatic approach that can be used to address a problem characterized by modeling difficulty associated with its dynamic nature and nonlinear aspects, and it makes use of heuristic knowledge. Thus, a fuzzy logic-based controller determines the control action according to a set of rules that represent the heuristic knowledge of the system to be controlled.

The diffuse logic control applied here is supported by "if-then"- type rules that correlate the inputs to the system and the desired outputs. The process can be summarized in three fundamental steps [29-30]: fuzzifying, making decisions, and de-fuzzifying. In the first step, the controller should convert the system inputs to diffuse logic language values using the relevant pertinence functions; that is, the numerical values of the inputs are converted into language values. Once the system has been fuzzified, the controller makes decisions based on the programmed control rules, always taking into account the knowledge of the system to determine the linguistic value corresponding to the optimal output. Lastly, de-fuzzification consists of converting the linguistic value into a numerical value corresponding to the value of the command signal that will act directly on the MR dampers.

The diffuse control design developed here to reduce the vibrations in structures is presented in Figure 5.

The semi-active control based on fuzzy logic used in this work is largely based on the system developed in [9] and [21]. The controller input variables used were the values of the displacement and velocity of the first floor of the analyzed structure, whereas the output variable corresponded to the voltage to be applied to the MR dampers.

The process of fuzzifying the controller input values first uses two linear functions -one for displacement and the other for velocity-to normalize the structure's responses in the range of the degree of pertinence defined by the membership functions as $[-1,1]$. The linear functions used for this purpose were:

$$
n_{d}=k_{d} x
$$




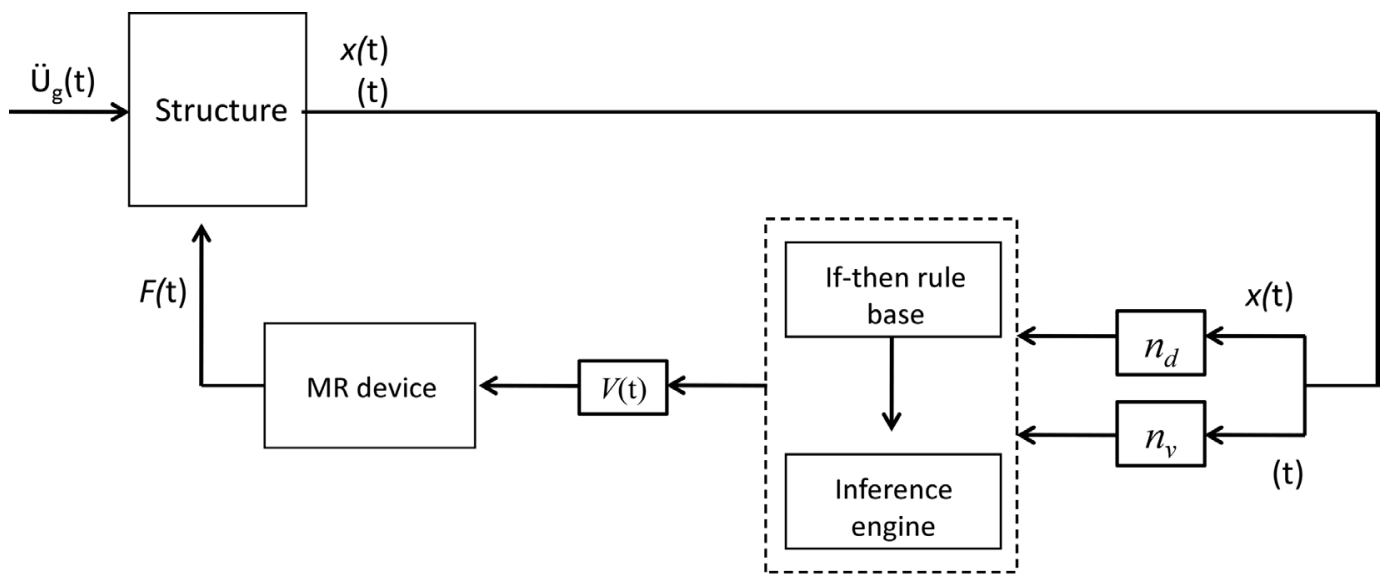

\section{Defuzzification Fuzzy rule base Fuzzification}

Figure 5. Control design developed based on fuzzy logic.

$$
n_{v}=k_{v} \dot{x}
$$

where $n_{d}$ and $n_{v}$ are the normalized input values in the range of the membership functions for displacement and velocity, respectively, and $k_{d}$ and $k_{v}$ are defined as displacement and velocity factors of scale, respectively. Based on parameter analysis, the factors of scale can be calculated as [21]:

$$
\begin{aligned}
& k_{d}=\frac{3}{x_{\max }} \\
& k_{v}=\frac{3}{\dot{x}_{\max }}
\end{aligned}
$$

where $x_{\max }$ and $\dot{x}_{\max }$ represent the maximum displacement and velocity values, respectively, of the non-controlled structure when subjected to any excitation. To determine the factors of scale in this work, the structure was subjected to a standard acceleration compatible with the excitations used in the system, considering that the system was initially prepared via time and magnitude scaling in accordance with its actual dimensions. Thus, the factors of scale to be used were determined to be $k_{d}=612$ and $k_{v}=20$.

Once the linear functions used to fuzzify the numerical inputs to the system have been determined, the next step is to define the membership functions of the controller inputs and the output. For the inputs, these functions consist of seven identical triangles that overlap one another placed in the middle of the base and are defined in the extension of the pertinence function range $[-1,1]$. The membership functions of the controller output consist of four identical triangles that overlap one another in the middle of the base and are defined over a membership function range $[0,1]$. It must be emphasized that the definition of the system's membership functions and their universes was achieved in [21] and constitute the set of rules adapted to the heuristic knowledge of the system studied here. Figures 6 and 7 present schemes of membership functions for the inputs and output of the designed controller, respectively.

The fuzzy linguistic values NL, NM, NS, ZO, PS, PM, and PL correspond to negative large, negative medium, negative small, zero, positive small, positive medium, and positive large, respectively.

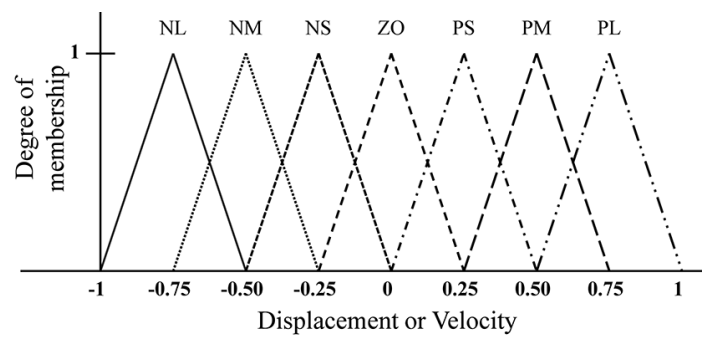

Figure 6. Controller input membership functions. 


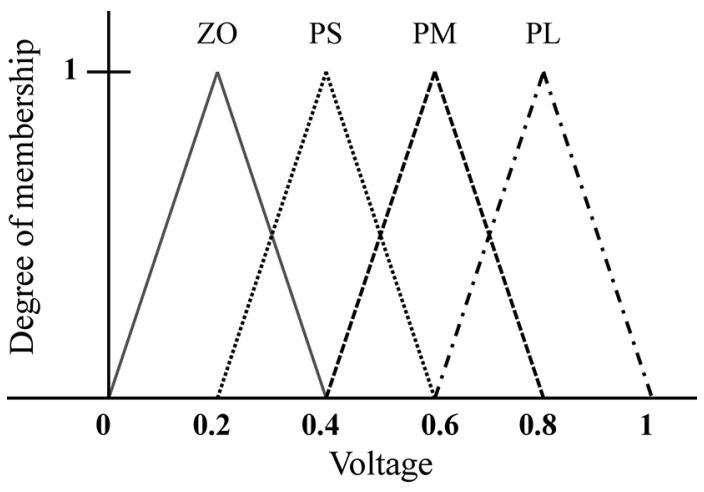

Figure 7. Controller output membership functions.

The decision-making stage is executed based on an inference engine linked to a knowledge base and functions according to the controller inputs' degrees of membership. A system of inference rules that facilitate efficiently calculating the voltage required to ensure that the control devices dissipate the energy entering the structure under analysis was used. This system is based on the following fundamental principle [21]: If the structure is out of its neutral position and tends to continue to move further, then the voltage applied must be increased to increase the damping power of the device. However, if the structure is out of its neutral position but tends to move closer, then little or no voltage is necessary. Table 1 presents the inference system developed in [21] and used in this work.

The degree of membership of the controller output will be determined using the well-known minimums method, which consists of selecting a degree of pertinence for the output equal to the lowest degree of pertinence among the inputs.

Table 1. Inference system employed.

\begin{tabular}{|c|c|c|c|c|c|c|c|}
\hline $\begin{array}{r}\text { VEL. } \\
\text { DIS. }\end{array}$ & NL & NM & NS & ZO & PS & PM & PL \\
\hline NL & PL & PL & PL & PM & ZO & ZO & ZO \\
\hline NM & PL & PL & PL & PS & ZO & ZO & PS \\
\hline NS & PL & PL & PL & ZO & ZO & PS & PM \\
\hline ZO & PL & PM & PS & ZO & PS & PM & PL \\
\hline PS & PM & PS & ZO & ZO & PL & PL & PL \\
\hline PM & PS & ZO & ZO & PS & PL & PL & PL \\
\hline PL & ZO & ZO & ZO & PM & PL & PL & PL \\
\hline
\end{tabular}

Finally, the de-fuzzification will be achieved via the centroid method, which permits determining the voltage value based on the overlapping areas of the output pertinence functions. The voltage value obtained using the centroid method lies in the universe $[0,1]$; therefore, a factor of scale that maps the output values of the diffuse universe $[0,1]$ to the real universe $[0,2.5]$ must be used. The factor of scale used in this work corresponds to:

$$
V=2,5\left(\frac{5}{3} s-\frac{1}{3}\right)
$$

where $V$ is the value of the voltage to be applied to the MR dampers and $s$ is the numerical value of the output obtained by the centroid method. The de-fuzzification process used for the controller here was designed in such a way that if the voltage $V$ surpasses the maximum value permitted in the analysis ( 2.5 volts), the value determined by equation (27) is automatically replaced with the stipulated maximum voltage.

\section{NUMERICAL MODEL EMPLOYED}

Here, the numerical model that serves as the basis for posterior applications of the control algorithms being proposed is presented. This model consists of a two-story frame structured building equipped with a pair of MR dampers at its base that are used to control the system. The numerical model is a theoretical idealization obtained from a real-scale experimental prototype installed in the Department of Structures, Geotechnics and Applied Geology at the University of Basilicata in Italy. The details of how the model parameters were determine can be found in [28, 31-33].

The building to be controlled by the numerical model is a two-story frame structure with each story having a floor-to-ceiling height of $2 \mathrm{~m}$. The building is rectangular in shape, with distances between the axes of the pillars of $3 \mathrm{~m}$ in the $\mathrm{X}$ direction and 4 $\mathrm{m}$ in the $\mathrm{Y}$ direction. Figure 8 shows a schematic of the model.

The mass $(\mathbf{M})$, rigidity $(\mathbf{K})$, and damping $(\mathbf{C})$ parameters of the model are condensed in matrices presented in (28), (29), and (30), respectively. Thus: 


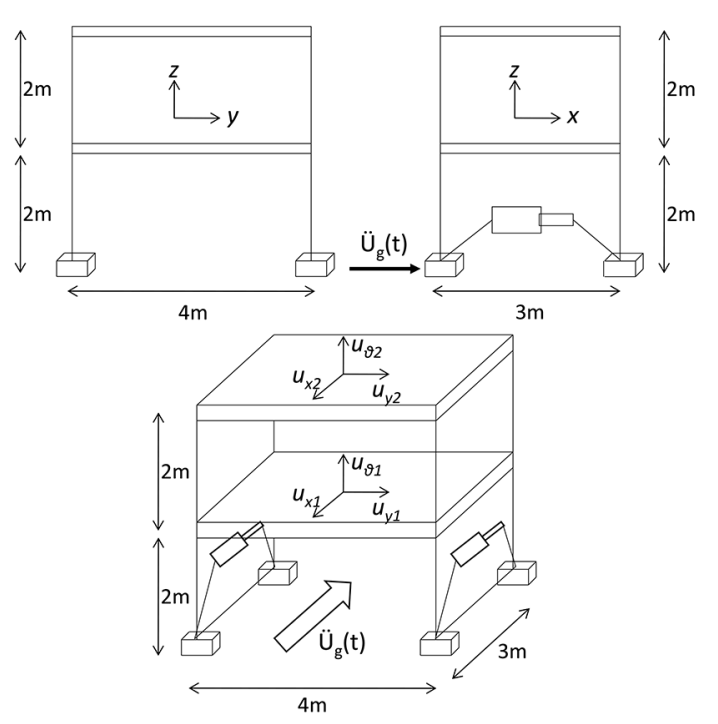

Figure 8. Schematic of the structural model used.

$$
\begin{aligned}
& M=\left[\begin{array}{cccccc}
2660 & 0 & 0 & 0 & 0 & 0 \\
0 & 2660 & 0 & 0 & 0 & 0 \\
0 & 0 & 7600 & 0 & 0 & 0 \\
0 & 0 & 0 & 2660 & 0 & 0 \\
0 & 0 & 0 & 0 & 2660 & 0 \\
0 & 0 & 0 & 0 & 0 & 7170
\end{array}\right] \\
& K=10^{3}\left[\begin{array}{cccccc}
28888 & 0 & 0 & -11596 & 0 & 0 \\
0 & 12303 & 0 & 0 & -5550 & 0 \\
0 & 0 & 114379 & 0 & 0 & -48376 \\
-11596 & 0 & 0 & 7621 & 0 & 0 \\
0 & -5550 & 0 & 0 & 4524 & 0 \\
0 & 0 & -48376 & 0 & 0 & 35330
\end{array}\right] \\
& C=\left[\begin{array}{cccccc}
266 & 0 & 0 & 0 & 0 & 0 \\
0 & 266 & 0 & 0 & 0 & 0 \\
0 & 0 & 760 & 0 & 0 & 0 \\
0 & 0 & 0 & 266 & 0 & 0 \\
0 & 0 & 0 & 0 & 266 & 0 \\
0 & 0 & 0 & 0 & 0 & 717
\end{array}\right]
\end{aligned}
$$

where the elements of mass associated with displacement are expressed in $\mathrm{kg}$ and the elements associated with rotation are expressed in $\mathrm{kg} \cdot \mathrm{m}^{2}$. The elements of rigidity associated with the displacement are presented in $\mathrm{N} / \mathrm{m}$, and those associated with rotation are presented in N.m. Finally, the damping elements associated with the displacement are expressed in $\mathrm{N} \cdot \mathrm{s} / \mathrm{m}$, and those associated with rotation are expressed in $\mathrm{N} \cdot \mathrm{s} \cdot \mathrm{m}$.

A modal analysis was conducted to determine the fundamental periods and frequencies of the structure $[28,31]$, and the results are listed in Table 2.
Table 2. Fundamental periods and frequencies of the model.

\begin{tabular}{|c|c|c|}
\hline Mode & Period (s) & Frequency $(\mathbf{H z})$ \\
\hline 1 & 0.25 & 3.95 \\
\hline 2 & 0.20 & 4.90 \\
\hline 3 & 0.15 & 6.58 \\
\hline 4 & 0.08 & 12.03 \\
\hline 5 & 0.06 & 17.99 \\
\hline 6 & 0.05 & 21.51 \\
\hline
\end{tabular}

The modes of vibration of the first floor are presented in the floorplan view shown in Figure 9.

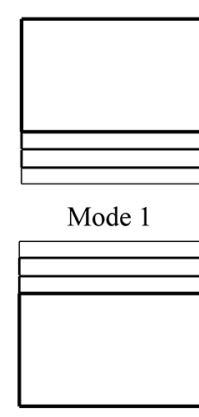

Mode 4

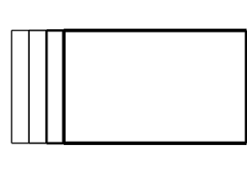

Mode 2

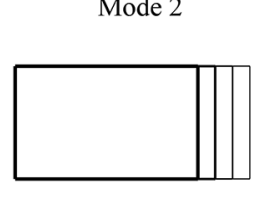

Mode 5

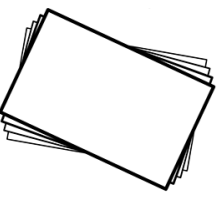

Mode 3

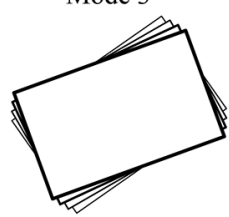

Mode 6
Figure 9. The model's modes of vibration of the first floor.

The MR dampers used in the numerical model correspond to real, commercially available dampers (MR RD-1005-3) developed by an American company: the Lord Corporation. These dampers' typical performance was emulated numerically using the phenomenological model described in [26].

Based on the trials conducted with MR RD-10053 dampers, it was possible to determine the main parameters and the mechanical characteristics that define their performance and the behavior of the dissipation mechanism. Table 3 summarizes the constant parameters obtained from the study reported in [34], which are necessary to model this particular damper.

In addition, the remaining parameters required for the phenomenological model were found to be variables that depended on the voltage applied to the damper. Furthermore, the alterations of these 
Table 3. Constant parameters of the RD-1005-3 MR damper.

\begin{tabular}{|c|c|c|c|c|c|}
\hline $\begin{array}{c}A \\
(\mathbf{m})\end{array}$ & $\begin{array}{c}\beta \\
(\mathbf{m})\end{array}$ & $\begin{array}{c}\gamma \\
(\mathbf{m})\end{array}$ & $\begin{array}{c}\boldsymbol{k}_{\boldsymbol{1}}\left(\boldsymbol{x}-\boldsymbol{x}_{\boldsymbol{0}}\right) \\
(\mathbf{N})\end{array}$ & $\begin{array}{c}\boldsymbol{k}_{\boldsymbol{0}} \\
(\mathbf{N} / \mathbf{m})\end{array}$ & $\mathbf{n}$ \\
\hline 20000 & 10000 & 10000 & 60 & 2020 & 2 \\
\hline
\end{tabular}

variables correspond closely to the behavior described by equations (31), (32), and (33):

$$
\begin{gathered}
a=58 v^{2}+112 v+51(\mathrm{~N}) \\
c_{0}=-1,25 v^{2}+4,15 v+1,62(\mathrm{Ns} / \mathrm{mm}) \\
c_{1}=11,53 v^{2}+37,68 v+11,87(\mathrm{Ns} / \mathrm{mm})
\end{gathered}
$$

\section{RESULTS AND ANALYSIS}

The numerical model was subjected to two different accelerations - " $A$ " and " $B$ "- at the base. The obtained accelerograms are natural in origin and reproduce the spectrum of a Type B soil according to the Italian classification OPCM3431. Each acceleration used was initially prepared by scaling in time and magnitude to ensure that they were compatible with the dimensions of the structure proposed for the numerical model. The overall objective was to use multiple excitations and accumulate sufficient information to make objective comparisons of the results obtained using the LQR algorithm and the control algorithms based on neural networks and fuzzy logic studied here.

In addition to comparisons of the various algorithms proposed for the semi-active control of structures using MR dampers, the performance of these devices as passive control mechanisms was also determined. To do so, the dampers did not receive any voltage $(V=0)$ during the analyzed time interval. That is, the MR dampers were used as if they were merely simple viscous-elastic dampers.

The first structure acceleration recorded was acceleration " $A$ ", which lasted for $40 \mathrm{~s}$ and had a maximum absolute amplitude of $1.47 \mathrm{~m} / \mathrm{s}^{2}$. The record of this acceleration is presented in Figure 10.

It must be emphasized that the dynamic response of the structure was calculated in terms of absolute

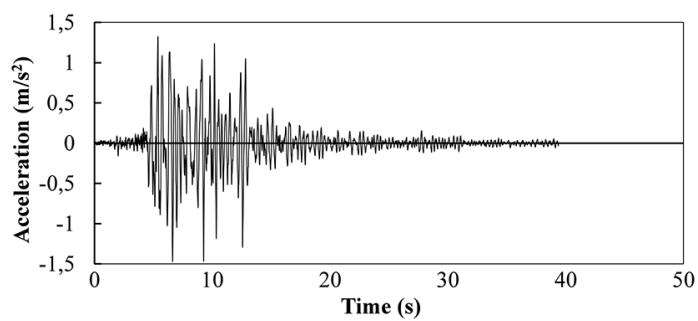

Figure 10. Accelerogram obtained for acceleration "A".

values using the root mean square (RMS) value, which provides a measure of the central tendency of the response values over the analyzed time period for each model characteristic.

When the MR dampers were tested in passive mode, the maximum displacements of the first and second stories were reduced by $20.41 \%$ and $20.91 \%$, respectively. Although the reductions in the percentages of the structural displacement peaks are not especially high, the effect of the control devices was notable in terms of the rapidity of the response peak reduction. This is clearly confirmed by the RMS values, which show reductions of $53.40 \%$ and $53.13 \%$ for the first and second floors, respectively, compared with those of the uncontrolled system. Analyzing the structural displacement while it was being administered by the semi-active control devices revealed that for pulse-type excitation (acceleration " $A$ "), the most efficient strategy was the LQR. This algorithm reduced the response peaks for both floors by approximately $58 \%$, whereas the RMS values of the response were reduced by $83 \%$. The strategies based on neural networks and fuzzy logic showed very similar behaviors, reducing the structure's response peaks by approximately $55 \%$ and the RMS values by $82 \%$ and $81 \%$, respectively.

Figure 11 presents the displacements of the first and second floors of the model when subjected to acceleration " $A$ " for the various controllers analyzed.

Velocity weighting followed the same steps used for the performance analysis of the various control strategies regarding their displacement response values. For excitation " $A$ ", the most efficient system was the LQR controller, which achieved reductions of approximately $63 \%$ and $85 \%$ in the peak values and response RMS, respectively. The ANN-based system was the second most effective in dissipating 

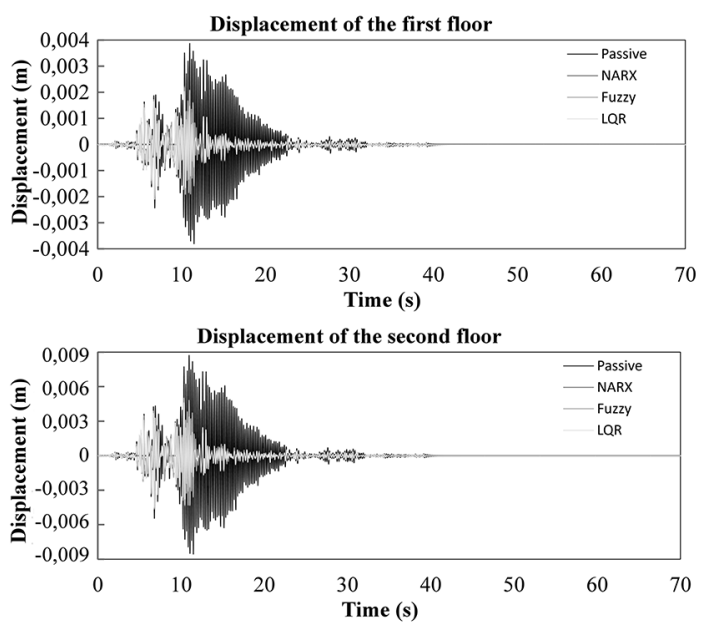

Figure 11. Displacement of the model when subjected to acceleration " $A$ " for the various controllers analyzed.

the system response, resulting in reductions of 59\% and $84 \%$, respectively, followed by the control system based on fuzzy logic, which achieved reductions of $58 \%$ and $83 \%$, respectively.

Figure 12 displays the velocities of the first and second floors of the model subjected to acceleration " $A$ " according to the various controllers analyzed.

Observing the semi-active control devices' performances when subjected to acceleration " $A$ " revealed some
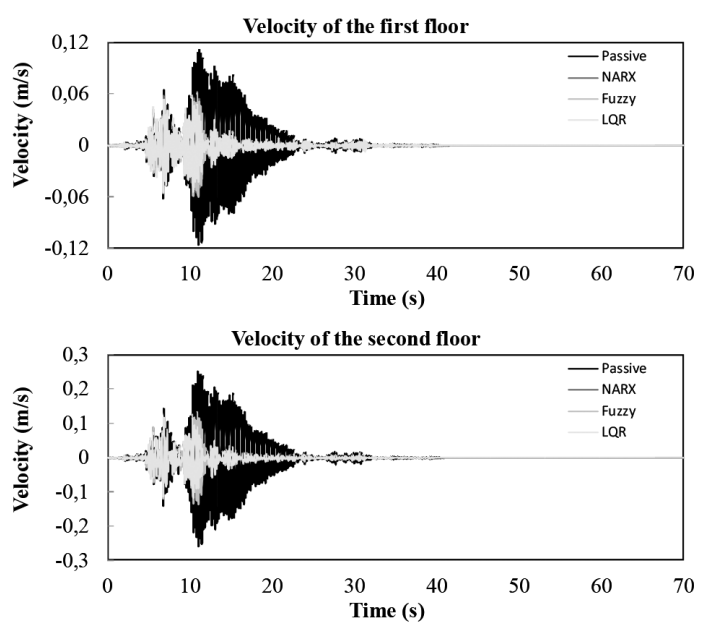

Figure 12. Velocities of the model subjected to acceleration " $A$ " for the various controllers analyzed. significant changes in the order of the controllers' efficiency. In terms of the percentage reduction in the response peaks, the most effective control algorithm for the structure as a whole was that based on neural networks, followed by the LQR and the fuzzy logicbased controller, which achieved reductions of $58 \%$, $57 \%$, and $55 \%$, respectively. Regarding reductions in RMS, the most efficient system was again the ANN-based controller, closely followed by the system based on fuzzy logic and the LQR, which resulted in percentage reductions of $83 \%, 83 \%$, and $81 \%$, respectively. Figure 13 shows the behavior of the two floors administered by the proposed control algorithms when submitted to excitation " $A$ ".

To more completely evaluate the results of the model when it was controlled by MR dampers, four performance indexes are calculated and used as in [35]. The first three are the normalized measurements of the displacement, velocity, and acceleration peaks of each floor, which are defined as:

$$
\begin{aligned}
& I_{1}=\max _{t, i}\left(\frac{\left|X_{i}(t)\right|}{X_{\text {max }}}\right) \\
& I_{2}=\max _{t, i}\left(\frac{\left|\dot{X}_{i}(t)\right|}{\dot{X}_{\max }}\right) \\
& I_{3}=\max _{t, i}\left(\frac{\left|\ddot{X}_{i}(t)\right|}{X_{\max }}\right)
\end{aligned}
$$
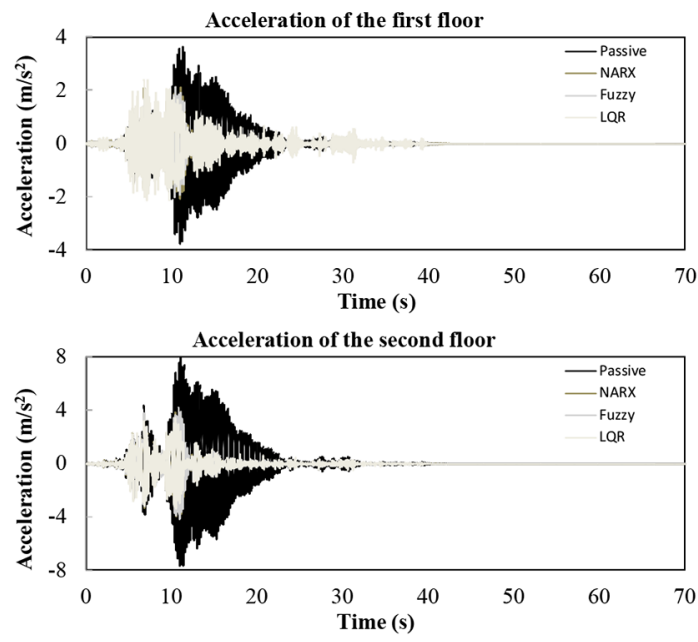

Figure 13. Accelerations of the model subjected to acceleration " $A$ " for the various controllers analyzed. 
where $X_{i}(t), \dot{X}_{i}(t)$, and $\ddot{X}_{i}(t)$ are the displacements, velocities, and accelerations, respectively, of each floor when the system is controlled and $X_{\max }, \dot{X}_{\max }$, $\ddot{X}_{\max }$ denote the maximum displacements, velocities, and accelerations of the uncontrolled system. The fourth and last proposed performance index consists of the normalized quantified displacement peaks between floors calculated using the expression:

$$
I_{4}=\max _{t, i}\left(\frac{\left|d_{i}(t)\right|}{d_{\max }}\right)
$$

where $d_{i}(t)$ is the relative displacement between the floors when the system is controlled and $d_{\max }$ is the peak value of the relative displacement between floors when the system is not controlled. As the performance indexes approach zero, the reduction in the response of the structure increases.

The obtained performance indexes corroborate the conclusion drawn from the analysis of the system responses; that is, the fuzzy logic-based control system shows satisfactory performance similar to that obtained for the ANN-based controller. For this case, all the performance indexes for the diffuse (fuzzy) system are higher for both floors than those estimated for the LQR controller, except for the normalized acceleration peak measurement of the first floor (index $I_{3}$ for the first floor), which is greater for the LQR control strategy. When the performance indexes for the control based on fuzzy logic are compared with those obtained for the control strategy using NARX networks, an equilibrium can be observed between them, especially in indexes $I_{1}$ and $I_{4}$, although the values achieved by the ANNbased control indicate slightly better performance. Figure 14 more clearly shows the differences between the obtained values and presents the different index values for all the controllers used in this work.

The second acceleration used to test the different modes of control differs from acceleration " $A$ " in several ways. First, the period of excitation was longer, exceeding $70 \mathrm{~s}$ for acceleration " $B$ ". Another important difference is that this RMS value of acceleration is higher, which implies that the structure response values are also higher and allows the control achieved by the MR dampers using the various strategies when subjected to a relatively heterogeneous excitation to be more thoroughly evaluated.
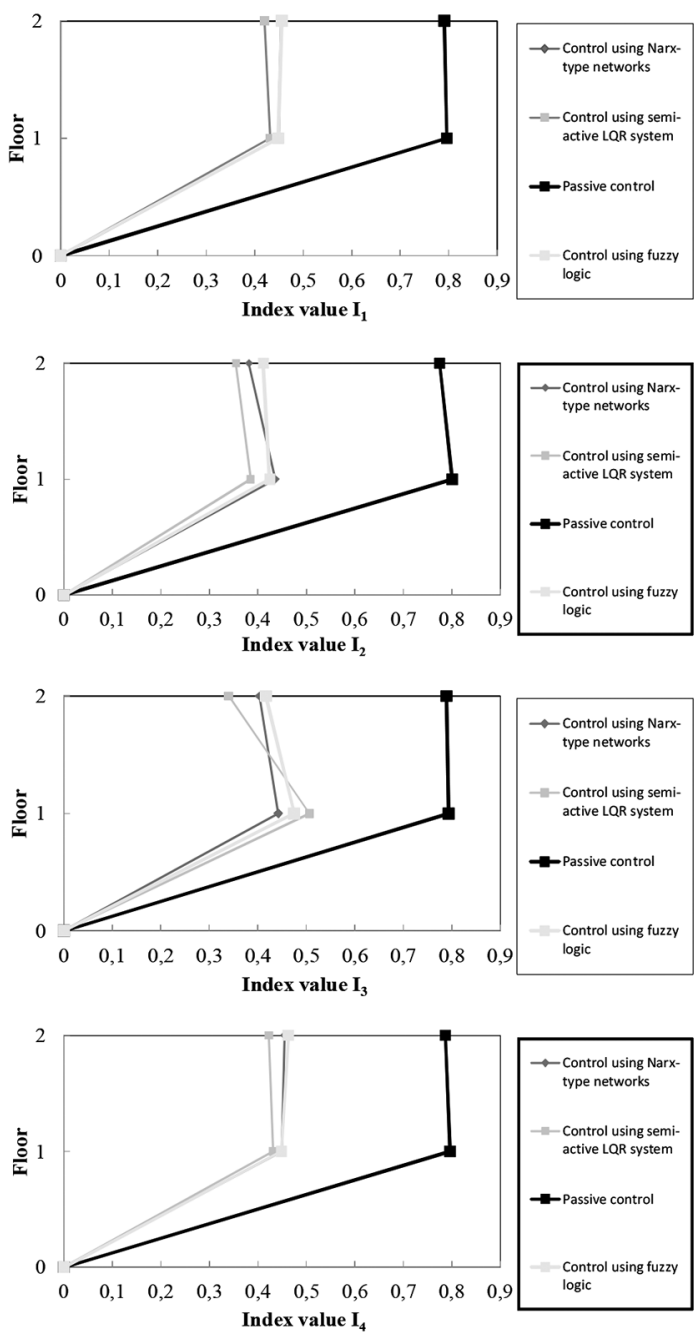

Figure 14. Variations in the performance indexes of the various control strategies analyzed when the structure is subjected to acceleration " $A$ ".

Figure 15 presents the record of the " $B$ " acceleration used to excite the base of the studied model. It should be that the time and magnitude scales of this record have been adjusted for compatibility with the structure's actual dimensions.

Analyzing the displacements of the structure during cyclic excitation (acceleration " $B$ ") of the structural model reveals that the most efficient controller is the ANN-based, which reduced the peaks and RMS response of the structure's displacements by $67 \%$ and $79 \%$, respectively. The fuzzy logic-based system closely followed the ANN-based on, with reduction 


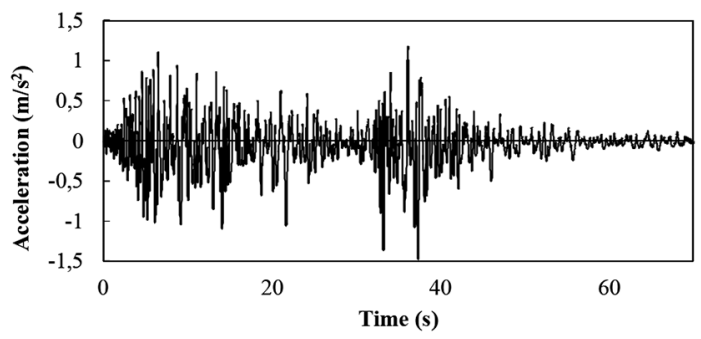

Figure 15. Time history of acceleration " $B$ ".

of approximately $66 \%$ and $75 \%$ in peak and RMS values, respectively. The LQR strategy exhibited the poorest performance, reducing the response peaks and RMS values by $62 \%$ and $74 \%$, respectively. The percentage reductions in displacement and velocity response peaks using passive control with no voltage applied were approximately $11 \%$, whereas the RMS values were reduced by approximately $33 \%$ for both floors. Compared to the response reductions obtained when the structure was subjected to acceleration " $A$ ", these values indicate poorer control performance, which means that the type of excitation influences the control results.

Figure 16 displays the displacements recorded in the structural model subjected to acceleration " $B$ " for the various control devices tested here.

The results obtained for excitation " $B$ " confirm that the best controller for reducing the velocity of structural system is the one based on ANNs, which achieved reductions of approximate $69 \%$ and $83 \%$ in the response peaks and velocity RMS, respectively, followed by the fuzzy logic-based control, which resulted in reductions of $68 \%$ and $78 \%$, respectively. The LQR controller exhibited the poorest performance, with reductions in response peak values and velocity RMS of approximately $62 \%$ and $77 \%$, respectively.

Figure 17 shows the velocity behavior of the two floors of the structure that are administered by the proposed control algorithms when the model is subjected to excitation " $B$ ".

The controller based on fuzzy logic was the most efficacious in reducing the acceleration peak values, followed by the ANN-based controller and then the controller based on the LQR algorithm. These devices achieved reductions of $67 \%, 57 \%$, and $55 \%$, respectively. In contrast, regarding the reduction of response RMS values, the most efficient controller was the ANN-based controller, followed by the system based on fuzzy logic and then the LQR controller, which resulted in reductions of $81 \%, 78 \%$, and $69 \%$, respectively. In the structure equipped with the passive system, the response was practically invariable in terms of the reductions in displacement and velocity. In this case, the reductions in peak and RMS values for the two floors were close to $14 \%$ and $34 \%$, respectively. Figure 18 presents the acceleration records of the first and second floors
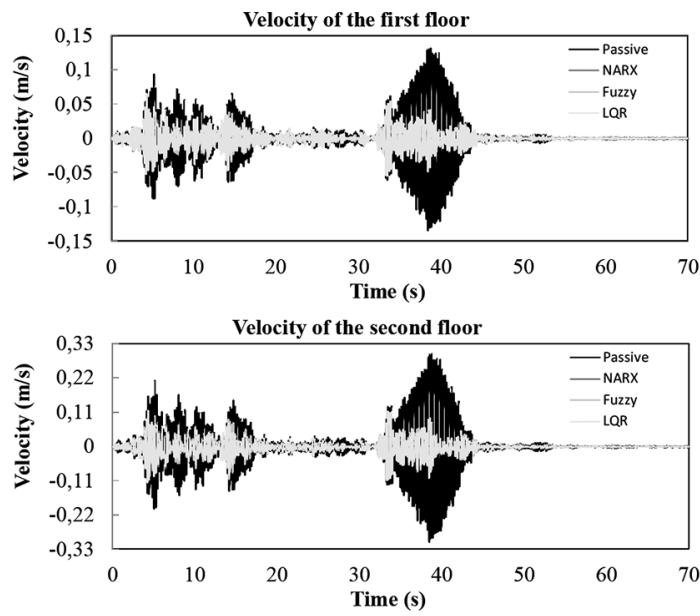

Figure 17. Velocities of the model subjected to excitation " $B$ " for the various controllers analyzed. 

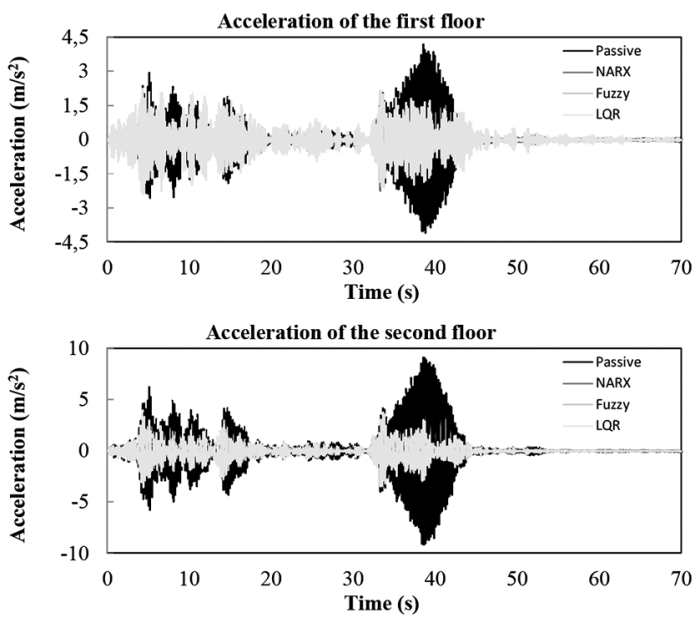

Figure 18. Accelerations of the model subjected to excitation " $B$ " for the various controllers analyzed.

of the model subjected to acceleration " $B$ " for the various controllers analyzed.

Comparing the values of the performance indexes for the various controllers tested using excitation " $B$ " reveals that the fuzzy logic-based controller is more efficient than the LQR controller for all evaluated indexes. However, although the performance indexes of the fuzzy logic-based controller confirm its ability to reduce peak values in the controller response, this device is less efficient than the NARX-based controller in almost all the indexes, except those related to the normalized responses of the acceleration of the two floors and the velocity performance index of the first floor. The results of the comparison of the performance indexes of the control algorithms studied here are presented in Figure 19.

Clearly, when subjected to excitation " $B$ ", the controller based on NARX neural networks achieves the greatest reductions in response peaks and RMS values. Figures 20 and 21 show the response reductions of the first and second floors of the model, respectively, when the system is administered by the ANN-based controller compared to the uncontrolled system.

\section{CONCLUSIONS}

The three control strategies were found to be interesting tools with potential applications as
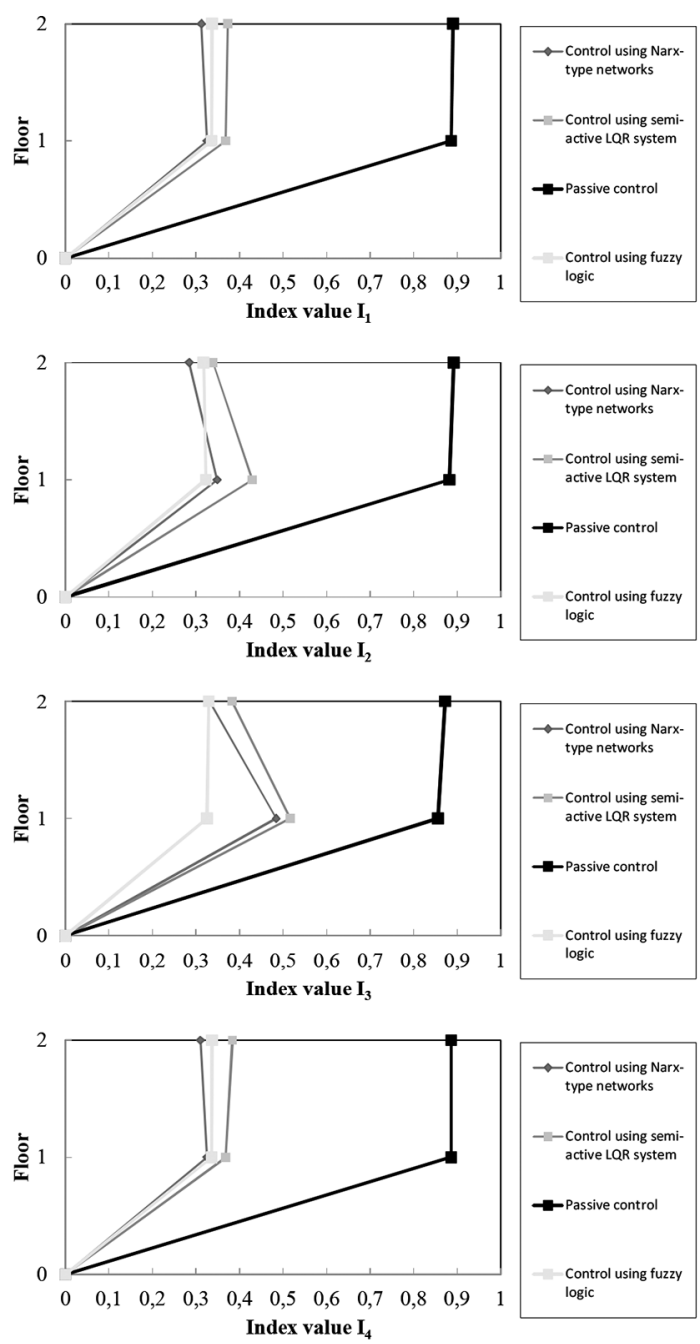

Figure 19.Variation of the performance indexes for the various studied control strategies when the structure is subjected to acceleration " $B$ ".

MR damper administrators. The different control algorithms were able to reduce the responses of the two-story structure studied here, confirm the potential utility of these semi-active control systems in buildings. The control designs based on intelligent systems show similar performances when subjected to pulse-type excitation but different performances when subjected to cyclical excitation. In the latter case, the ANN-based control algorithm was generally more efficient than the one based on fuzzy logic.

Generally, the controller design based on neural networks was the most reliable and efficient in 

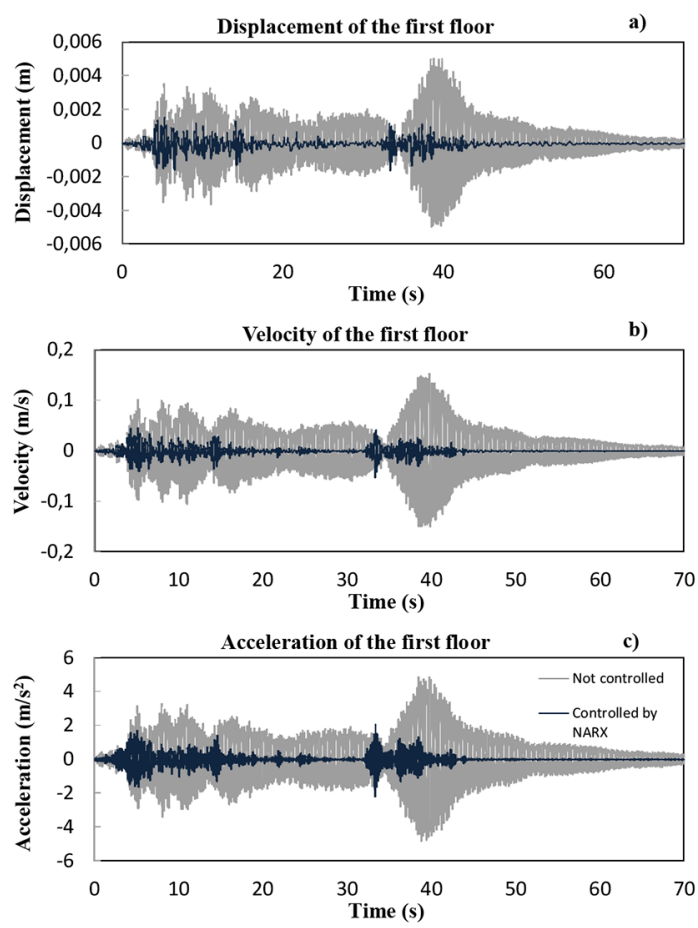

Figure 20. Responses of the first floor of the model without and with control based on NARX neural networks when subjected to excitation " $B$ ": a) Displacement, b) Velocity, and c) Acceleration.

reducing the response values of the analyzed model. The predictive model and the inverse model performed adequately and in a synchronized manner despite the complexities of the problem and the solution involved.

The biggest limitation of this alternative control system is that processing requires an excessive amount of time, which makes the real-time implementation of this system difficult or expensive because of the need for components with very high processing power.

While measuring the time processing of the alternative control strategy, the LQR controller was observed to be the most efficient algorithm tested, requiring approximately $4.33 \mathrm{~min}$ to completely process the studied cases. The second fastest algorithm corresponded to the controller based on fuzzy logic, which required an average time of 6 min. Finally, the ANN-based control strategy was the slowest, exhibiting an average processing
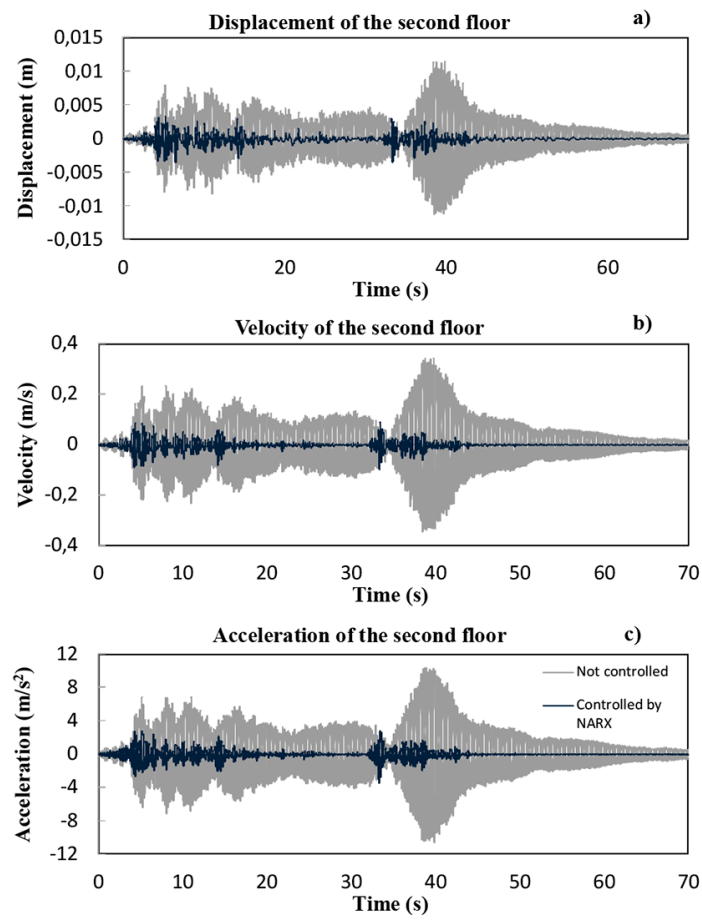

Figure 21. Responses of the second floor of the model without and with control based on NARX neural networks when subjected to acceleration " $B$ ": a) Displacement, b) Velocity, and c) Acceleration.

time of $25 \mathrm{~min}$. The calculations were performed using a basic computer equipped with a Core 2 Duo T6400 processor with a 2-GHz clock and 4 GB of RAM available.

The control design using fuzzy logic to select the command signal may be the most balanced control strategy among the four analyzed here. This controller combines notable efficiency with rapid processing and simplicity. Practically, the control algorithm based on fuzzy logic would be easy to implement, depending only on the heuristic knowledge of the system to be administered. Its main disadvantage is that its inference system bases its decisions on the displacements and velocities of the structure, which are typically obtained via processes integrating the acceleration response values and are subject to the eventual presence of low frequencies and background interference that would need to be removed through the use of a high-pass filter in most practical situations. 
The LQR is likely the most modest semi-active controller strategy, although it exhibited very satisfactory results in reducing velocity and displacement values when the structure was subjected to pulse-type acceleration. This control strategy is robust and particularly rapid, and these features are its main advantages relative to the other control strategies analyzed. However, its main disadvantages are its irregular performance and its considerable sensitivity to some parameters

\section{ACKNOWLEDGEMENTS}

The authors wish to thank the Universidade de Brasilia, the Universidad Nacional de Colombia (Medellin Campus), and the CNPq for supporting the development of this work.

\section{REFERENCES}

[1] T. Soong and G. Dargush. "Passive Energy Dissipation Systems in Structural Engineering”. John Wiley \& Sons. Chichester, England. 1997.

[2] B. Spencer Jr. and T. Soong. "New applications and development of active, semi-active and hybrid control techniques for seismic and nonseismic vibration in the USA". International Post-SMiRT Conference Seminar on Seismic Isolation, Passive Energy Dissipation and Active Control of Vibration of Structures. Cheju, Korea. 1999.

[3] D. Gomez, J. Marulanda and P. Thomson. "Sistemas de control para la protección de estructuras civiles sometidas a cargas dinámicas [Control systems for the protection of civil structures under dynamic loads]". Revista DYNA. Vol. 155, pp. 77-89. 2008.

[4] S. Dyke. "Acceleration feedback control strategies for active and semi-active control systems: modeling, algorithm development, and experimental verification". PhD Dissertation. Department of Civil Engineering and Geological Sciences Notre Dame. Indiana, USA. 1996.

[5] G. Housner, L. Bergman, T. Caughey, A. Chassiakos, R. Claus, S. Masri, R. Skelton, T. Soong, B. Spencer and J. Yao. "Structural Control: Past, Present and Future". Journal of Engineering Mechanics. Vol. 123, Issue 9, pp. 897-971. 1997.
[6] M. Symans and M. Constantinou. "Semiactive control systems for seismic protection of structures: a state-of-the-art review". Engineering Structures. Vol. 21, Issue 6, pp. 469-487. 1999.

[7] B. Spencer Jr. and S. Nagarajaiah. "State of the art of structural control". Journal of Structural Engineering. Vol. 129, Issue 7, pp. 845-856. 2003.

[8] S. Dyke, B. Spencer, M. Sain and J. Carlson. "Modeling and control of magnetorheological dampers for seismic response reduction". Smart Materials and Structures. Vol. 5, pp. 565-75. 1996.

[9] C. Dias. "Fuzzy control of magnetorheological dampers for vibration reduction of seismically excited structures". Ph.D. Dissertation. Department of Civil and Environmental Engineering, Florida State University, Florida, USA. 2005.

[10] G. Yang. "Large-scale magnetorheological fluid damper for vibration mitigation: modeling, testing and control". PhD Dissertation. Department of Civil Engineering and Geological Sciences Notre Dame, Indiana, USA. 2001.

[11] Y. Kim, R. Langari and S. Hurlebaus. "Semiactive nonlinear control of a building with magnetorheological damper system". Mechanical Systems and Signal Processing. Vol. 23, Issue 2, pp. 300-315. 2009.

[12] H. Jung, K. Choi, B. Spencer Jr. and I. Lee. "Application of some semi-active control algorithms to a smart base-isolated building employing MR dampers". Structural Control and Health Monitoring. Vol. 13, pp. 693704. 2006.

[13] O. Yoshida and S. Dyke. "Seismic control of a nonlinear benchmark building using smart dampers". Journal of Engineering Mechanics. Vol. 130, pp. 386-392. 2004.

[14] H. Jung, B. Spencer Jr., and I. Lee. "Control of seismically excited cable-stayed bridge employing magnetorheological fluid dampers". Journal of Structural Engineering. Vol. 129, Issue 7, pp. 873-883. 2003.

[15] E. Baris, A. Masato and F. Yozo. "Investigation of semi-active control for seismic protection of elevated highway bridges". Engineering Structures. Vol. 24, Issue 3, pp. 281-293. 2002. 
[16] Z. Li, C. Chang, and B. Spencer Jr. "Intelligent technology-based control of motion and vibration using MR dampers". Earthquake Engineering and Engineering Vibration. Vol. 1, Issue 1, pp. 100-110. 2002.

[17] Z. Xu, Y. Shen and Y. Guo. "Semi-active control of structures incorporated with magnetorheological dampers using neural networks". Smart Materials and Structures. Vol. 12, Issue 1, pp. 80-87. 2003.

[18] D. Wang and W. Liao. "Modeling and control of magnetorheological fluid dampers using neural networks". Smart Materials and Structures. Vol. 14, Issue 1, pp. 111-126. 2004.

[19] H. Lee, H. Jung, W. Yun, and I. Lee. "Semiactive neuro-control using MR damper for base-isolated benchmark problem". The Eighteenth KKCNN Symposium on Civil Engineering-KAIST5. Taiwan. 2005.

[20] Y. Guo, S. Fei, and Z. Dongxu. "Simulation analysis on intelligent structures with magnetorheological dampers". Journal of Intelligent Material Systems and Structures. Vol. 19, Issue 6, pp. 715-726, 2008.

[21] Y. Liu, F. Gordaninejad, C. Evrensel, and G. Hitchcock. "An experimental study on fuzzy logic vibration control of a bridge using fail-safe magneto-rheological fluid dampers". Smart Systems and Materials 2001-Smart Systems for Bridges, Structures, and Highways. Newport Beach, USA. 2001.

[22] Y. Liu, F. Gordaninejad, C. Evrensel, X. Wang, and G. Hitchcock. "Comparative study on vibration control of a scaled bridge using fail-safe magneto-rheological fluid dampers". Journal of Structural Engineering. Vol. 131, Issue 5, pp. 743-751. 2005.

[23] H. Kim and P. Roschke. "Design of fuzzy logic controller for smart base isolation system using genetic algorithm". Engineering Structures. Vol. 28, Issue 1, pp. 84-96. 2006.

[24] H. Liu, K. Nonami, and T. Hagiwara. "Active following fuzzy output feedback sliding mode control of real-vehicle semi-active suspensions". Journal of Sound and Vibration. Vol. 314, Issues 1-2, pp. 39-52. 2008.

[25] C. Dias and M. Abdullah. "Structural vibration reduction using self-tuning fuzzy control of magnetorheological dampers". Bulletin of Earthquake Engineering. Vol. 8, Issue 4, pp. 1037-1054. 2010.

[26] B. Spencer Jr., S. Dyke, M. Sain and J. Carlson. "Phenomenological model of a magnetorheological damper". Journal of Engineering Mechanics. Vol. 123, Issue 3, pp. 230-238. 1997.

[27] X. He and H. Asada. "A new method for identifying orders of input-output models for nonlinear dynamic systems". Proceedings of the American Control Conference. San Francisco, USA. 1993.

[28] L. Lara. "Estudo de algoritmos de controle semi-ativo aplicados a amortecedores magnetorréologicos [Study of semiactive control algorithms applied to magnetorheological dampers]". Ph.D. Dissertation. Universidade de Brasília, Brasilia, Brazil. 2011.

[29] M. Aldawod, B. Samali, F. Naghdy, and K. Kwok. "Active control of a long wind response of tall building using a fuzzy controller". Engineering Structures. Vol. 23, pp. 1512-1522. 2001.

[30] F. Marazzi and G. Magonette. "Active and semi-active control of structures: a comparison". European Meeting on Intelligent Structures. Ishia, Italy. 2001.

[31] R.B. Carneiro. "Controle semi-ativo de vibrações em estruturas utilizando amortecedor magnetorreológico [Semi-active control structures of vibrations involving magneto-rheological dampers]". Ph.D. Dissertation. Universidade de Brasilia, Brasília, Brazil. 2009.

[32] A. Contento, V. Gattulli, M. Lepidi, and F. Potenza. "Identificazione di modelli per un protótipo sperimentale di telaio tridimensionale com controventi semi-attivi [Identification of models for an experimental prototype of a three-dimensional frame with semi-active control]". Relatório técnico No 2 . DISAT, Università degli studi dell'Aquila, L'Aquila, Italy. 2006.

[33] L. Lara, J. Brito and Y. Valencia. "Reducción de vibraciones en un edificio mediante la utilización de amortiguadores magnetoreológicos [Reducing vibrations in a building using magnetorheological dampers]". Revista Dyna. No 171, pp. 205-214. 2012. 
[34] M. Basili. "Controllo semi attivo di strutture adiacenti mediante dispositivi magnetoreologici: teoria, sperimentazione and modellazione [Semi-active control of adjacent structures using magnetorheological devices: theory, experiments, and modeling]".
Ph.D. Dissertation. Università degli studi di Roma "La Sapienza", Roma, Italia. 2006.

[35] L.M. Jansen and S.J. Dyke. "Semiactive control strategies for MR dampers: comparative study". Journal of Engineering Mechanics. Vol. 126, pp. 795-803. 2000.

Nomenclature

\begin{tabular}{|c|c|}
\hline Symbol & Description \\
\hline$A$ & State matrix \\
\hline$A N N$ & Artificial neural network \\
\hline$B$ & Location matrix associated with the position of the MR damper \\
\hline$C$ & Damper matrix \\
\hline$D$ & Matrix defining the location of the control forces \\
\hline$d_{i}(t)$ & Relative displacement between floors in the controlled system \\
\hline$d_{\max }$ & Displacement of the relative peak between floors in the uncontrolled system \\
\hline$E$ & Matrix defining the location of external excitation \\
\hline$f(n)$ & Output control force in the prediction model \\
\hline$F(t)$ & Force applied by the MR dampers \\
\hline$f(t)$ & Load vector \\
\hline$f(t)$ & Force calculated by the prediction model \\
\hline$G(t)$ & Control gain \\
\hline$H$ & Location matrix associated with the load vector \\
\hline$H$ & Unit step function \\
\hline$H$ & Hamiltonian \\
\hline$I$ & Identity matrix $(n \times n)$ \\
\hline$I_{1}$ & Performance index of the displacement peak \\
\hline$I_{2}$ & Performance index of the velocity peak \\
\hline$I_{3}$ & Performance index of the acceleration peak \\
\hline$I_{4}$ & Performance index of the peak displacement between the normalized floors \\
\hline$J$ & Performance index of the LQR method \\
\hline$K$ & Stiffness matrix \\
\hline$k_{d}$ & Factor of scale for displacement \\
\hline$k_{v}$ & Factor of scale for velocity \\
\hline$L$ & Lagrangian \\
\hline$L Q R$ & Linear quadratic regulator \\
\hline$M$ & Mass matrix \\
\hline$m$ & Dimension of control force vector \\
\hline NARX & Nonlinear autoregressive exogenous model \\
\hline$N L$ & Negative large \\
\hline$N M$ & Negative medium \\
\hline$N S$ & Negative small \\
\hline$n$ & Degrees of freedom \\
\hline$n_{d}$ & Linear function of displacement \\
\hline$n_{v}$ & Linear function of velocity \\
\hline$P(t)$ & Riccati matrix \\
\hline$P L$ & Positive large \\
\hline$P M$ & Positive medium \\
\hline$P S$ & Positive small \\
\hline$Q$ & Weighting matrix $(2 n \times 2 n)$ \\
\hline
\end{tabular}




\begin{tabular}{|c|l|}
\hline Symbol & \\
\hline$R$ & Weighting matrix $(m \times m)$ \\
\hline$r$ & Dimension of load vector \\
\hline$s$ & Output obtained using the centroid method \\
\hline$S(n)$ & Neural network entries \\
\hline$u$ & Real force produced by the MR damper \\
\hline$u_{c}$ & Desired control force \\
\hline$u(t)$ & Control vector \\
\hline$V(t)$ & Voltage to apply to the MR damper \\
\hline$v(n)$ & Output voltage of the inverse model \\
\hline$V_{\max }$ & Saturation voltage of the control device \\
\hline$X_{i}(t)$ & Relative displacement of each floor of the controlled system \\
\hline$\dot{X}_{i}(t)$ & Relative velocity of each floor of the controlled system \\
\hline$\ddot{X}_{i}(t)$ & Relative acceleration of each floor of the controlled system \\
\hline$x(t)$ & Displacement vector of the structure \\
\hline$\dot{x}(t)$ & Velocity vector of the structure \\
\hline$\ddot{x}(t)$ & Acceleration vector of the structure \\
\hline$x_{\max }$ & Maximum displacement of the uncontrolled system \\
\hline$\dot{x}_{\max }$ & Maximum velocity of the uncontrolled system \\
\hline$\ddot{x}_{\max }$ & Maximum acceleration of the uncontrolled system \\
\hline$\ddot{U}_{g}(t)$ & Ground motion \\
\hline$z(t)$ & State vector \\
\hline$\dot{z}(t)$ & First derivate of the state vector \\
\hline$\hat{z}(t)$ & Estimated state vector \\
\hline$z^{-1}$ & Delay line \\
\hline$Z O$ & Zero \\
\hline$O$ & Zero matrix $(n x n)$ \\
\hline$\lambda(t)$ & Lagrange multiplier \\
\hline
\end{tabular}

